Published in final edited form as:

Nature. 2007 October 11; 449(7163): 713-716.

\title{
Quantifying the evolutionary dynamics of language
}

\author{
Erez Lieberman $1,2,3,{ }^{*}$, Jean-Baptiste Michel ${ }^{1,4,}{ }^{*}$, Joe Jackson ${ }^{1}$, Tina Tang ${ }^{1}$, and Martin A. \\ Nowak $^{1}$ \\ 1 Program for Evolutionary Dynamics, Department of Organismic and Evolutionary Biology, Department of \\ Mathematics, Harvard University, Cambridge, MA 02138, USA
}

2Department of Applied Mathematics, Harvard University, Cambridge, MA 02138, USA

3Harvard-MIT Division of Health Sciences and Technology, Massachusetts Institute of Technology, Cambridge, MA 02139, USA

4Department of Systems Biology, Harvard Medical School, Boston, MA 02115, USA.

\begin{abstract}
Human language is based on grammatical rules ${ }^{1-4}$. Cultural evolution allows these rules to change over time ${ }^{5}$. Rules compete with each other: as new rules rise to prominence, old ones die away. To quantify the dynamics of language evolution, we studied the regularization of English verbs over the last 1200 years. Although an elaborate system of productive conjugations existed in English's protoGermanic ancestor, modern English uses the dental suffix, -ed, to signify past tense ${ }^{6}$. Here, we describe the emergence of this linguistic rule amidst the evolutionary decay of its exceptions, known to us as irregular verbs. We have generated a dataset of verbs whose conjugations have been evolving for over a millennium, tracking inflectional changes to 177 Old English irregulars. Of these irregulars, 145 remained irregular in Middle English and 98 are still irregular today. We study how the rate of regularization depends on the frequency of word usage. The half-life of an irregular verb scales as the square root of its usage frequency: a verb that is 100 times less frequent regularizes 10 times as fast. Our study provides a quantitative analysis of the regularization process by which ancestral forms gradually yield to an emerging linguistic rule.
\end{abstract}

Natural languages comprise elaborate systems of rules which enable one speaker to communicate with another ${ }^{7}$. These rules serve to simplify the production of language and enable an infinite array of comprehensible formulations ${ }^{8-10}$. Yet each rule has exceptions, and even the rules themselves wax and wane over centuries and millennia ${ }^{11,12}$.

Verbs which obey standard rules of conjugation in their native language are called regular verbs $^{13}$. In the modern English language, regular verbs are conjugated into the simple past and past participial forms by appending the dental suffix -ed to the root (for instance, talk/talked/ talked). Irregular verbs obey antiquated rules (sing/sang/sung) or in some cases, no rule at all (go/went) ${ }^{14,15}$.

New verbs entering English universally obey the regular conjugation (google/googled/ googled), and many irregular verbs eventually regularize. Regular verbs become irregular much more rarely: for every sneak that snuck in 16 , there are many more flews that flied out.

Reprints and permissions information is available at npg.nature.com/reprintsandpermissions. The authors declare no competing financial interests. Correspondence and requests for materials should be addressed to M. A. N. (martin_nowak@ harvard.edu).

These authors contributed equally to this work.

Supplementary Information is linked to the online version of the paper at www.nature.com/nature. 
Although less than $3 \%$ of modern verbs are irregular, the ten most common verbs are all irregular (be, have, do, go, say, can, will, see, take, get). The irregular verbs are heavily biased towards high frequencies of occurrence ${ }^{17,18}$. Linguists have suggested an evolutionary hypothesis underlying the frequency distribution of irregular verbs: uncommon irregular verbs tend to disappear more rapidly because they are less readily learned, and more rapidly forgotten 19,20 .

In order to study this phenomenon quantitatively, we studied verb inflection beginning with Old English (the language of Beowulf, spoken circa $800 \mathrm{CE}$ ), continuing through Middle English (the language of Chaucer's Canterbury Tales, spoken circa $1200 \mathrm{CE}$ ), and ending with Modern English, the language as it is spoken today. The modern -ed rule descends from Old English 'weak' conjugation, which applied to 3/4 of all Old English verbs ${ }^{21}$. The exceptions - ancestors of the modern irregulars - were mostly members of the so-called 'strong' verbs. There are 7 different classes of strong verbs with exemplars among the modern English irregulars, each with distinguishing markers that often include characteristic vowel shifts. Though stable coexistence of multiple rules is one possible outcome of rule dynamics, this is not what occurred in English verb inflection 22 . We therefore define regularity with respect to the modern -ed rule, and call all these exceptional forms 'irregular'.

We consulted a large collection of grammar textbooks describing verb inflection in these earlier epochs, and hand annotated every irregular verb they described. (See Supplementary Information.) This provided us with a list of irregular verbs from ancestral forms of English. Eliminating verbs which were no longer part of Modern English, we compiled a list of 177 Old English irregular verbs which remain part of the language to this day. Of these 177 Old English irregulars, 145 remained irregular in Middle English, and 98 are still irregular in Modern English. Verbs such as help, grip, and laugh, which were once irregular, have become regular with the passing of time.

Next we obtained frequency data for all verbs by using the CELEX corpus, which contains 17.9 million words from a wide variety of textual sources ${ }^{23}$. For each of our 177 verbs we calculated the frequency of occurrence among all verbs. We subdivided the frequency spectrum into six logarithmically spaced bins from $10^{-6}$ to 1 . Figure 1a shows the number of irregular verbs in each frequency bin. There are only two verbs, be and have, in the highest frequency bin, whose mean frequency is $>0.1$. Both remain irregular to the present day. There are eleven irregular verbs in the second bin, with mean frequency between 0.01 and 0.1 . These eleven verbs have all remained irregular from Old English to Modern English. In the third frequency bin, 0.001 to 0.01 , we find that 37 irregulars of Old English all remained irregular in Middle English, but only 33 of them are irregular in Modern English. Four verbs in this frequency range, help, reach, walk, and work, underwent regularization. In the fourth frequency bin, $10^{-4}$ to $10^{-3}, 65$ irregulars of Old English have left 57 in Middle and 37 in Modern English. In the fifth frequency bin, $10^{-5}$ to $10^{-4}, 50$ irregulars of Old English have left 29 in Middle and 14 in Modern English. In the sixth frequency bin, $10^{-6}$ to $10^{-5}, 12$ irregulars of Old English decline to 9 in Middle and only one in Modern English: slink, a verb which aptly describes this quiet process of disappearance.

Plotting the number of irregular verbs against their frequency generates a unimodal distribution with a peak between $10^{-4}$ and $10^{-3}$. This unimodal distribution again demonstrates that irregular verbs are not an arbitrary subset of all verbs, because a random subset of verbs (such as all verbs that contain the letter ' $m$ ') would follow a power law distribution with a slope of three-fourths 24,25 .

Four of our six frequency bins, those between $10^{-6}$ and $10^{-2}$, allow us to estimate the relative regularization rates of irregular verbs. Calculating the relative regularization rates of verbs of 
different frequencies is independent of time, which makes the dating of Old and Middle English irrelevant for this calculation. We can draw regularization rate versus frequency and fit a straight line in a log-log plot (Figure 1b). Comparing Old and Modern English we obtain a slope of about $-0: 51$. Therefore, an irregular verb which is 100 times less frequent is regularized 10 times as fast. In other words, the half-life of irregular verbs is proportional to the square root of their frequency. Comparing Middle and Modern English we find a slope of about -0:48, consistent with the previous result. Both comparisons show that low frequency irregulars are selectively forgotten.

Figure 2a shows the exponential decay of the irregular verbs in the four frequency bins between $10^{-6}$ and $10^{-2}$ as a function of time. From these data, which depend on the dating of Old and Middle English, we can estimate actual half-lives of the irregular verbs in different frequency bins. Irregular verbs that occur with a frequency between $10^{-6}$ and $10^{-5}$ have a half-life of about 300 years, while those with a frequency between $10^{-4}$ and $10^{-3}$ have a half-life of 2000 years. If we fit half-life versus frequency with a straight line in a log-log plot, we obtain a slope of 0.50 , which again suggests that the half-life of irregular verbs is proportional to approximately the square root of their frequency (Figure 2b). It is noteworthy that various methods of fitting the data give the same results.

We cannot directly determine the regularization rate for frequency bins above $10^{-2}$, because regularization is so slow that no event was observed in the time span of our data. But we can extrapolate. For instance, the half-life of verbs with frequencies between $10^{-2}$ and $10^{-1}$ should be 14,400 years. For these bins, the population is so small and the half-life so long that we may not see a regularization event in the lifetime of the English language.

To test whether the dynamics within individual competing rules were captured by our global analysis, we studied the decay of individual classes of strong verbs (e.g., hit/hit/hit, hurt/hurt/ hurt; draw/drew/drawn, grow/grew/grown ${ }^{26}$. Although our resolution is limited by the small sample size, exponential decay is once again observed, with similar exponents. (See Supplementary Figure S1.) Like a Cheshire cat, dying rules vanish one instance at a time, leaving behind a unimodal frown.

Because adequate corpora of Old and Middle English do not exist, we have estimated the frequency of an irregular verb of Old and Middle English by the frequency of the corresponding (regular or irregular) verb of Modern English. ${ }^{27}$ A large fraction of verbs would have had to change frequency by several orders of magnitude in order to interfere with the effects observed. To verify that large changes in frequency are rare, we compared frequency data from CELEX with frequencies drawn from the largest available corpus of Middle English texts ${ }^{28}$. Out of fifty verbs, only five had frequency changes greater than a factor of 10. (See Supplementary Figure S2.)

Our analysis covers a vast period, spanning the Norman invasion and the invention of the printing press, but these events did not upset the dynamics of English regularization.

Therefore, it is possible to retrospectively trace the evolution of the irregular verbs, moving backwards in time from the observed Modern distribution and up through Middle and Old English. Going still further back in time allows us to explore the effects of completely undoing the frequency-dependent selective process which the irregular verbs have undergone.

Eventually, the shape of the curve changes from unimodal to a power law decline with slope nearly $-3 / 4$ (Figure 3 ). This finding is remarkably consistent with the fact that random subsets of verbs (and of all types of words) exhibit such a Zipfian distribution. The observed irregular verb distribution is the result of selective pressure on a random collection of ancestral verbs. 
We can also make predictions about the future of the past tense. By the time one verb from the set $\{$ begin, break, bring, buy, choose, draw, drink, drive, eat, fall $\}$ will regularize, five verbs from the set $\{$ bid, dive, heave, shear, shed, slay, slit, sow, sting, stink\} will be regularized. If the current trends continue, only 83 of the 177 verbs studied will be irregular in 2500 .

What will be the next irregular verb to regularize? Most likely it will be wed/wed/wed. Wed's frequency is only 4.2 uses per million verbs, ranking at the very bottom of the modern irregulars. Indeed, it is already being replaced in many contexts by wed/wedded/wedded. Now is your last chance to be a newly-wed. The married couples of the future can only hope for wedded bliss.

In prior millennia, many rules vied for control of English language conjugation, and fossils of those rules remain to this day. Yet from this primordial soup of conjugations, the dental suffix -ed emerged triumphant. The competing rules are long dead, and unfamiliar even to welleducated native speakers. These rules disappeared because of the gradual erosion of their instances by a process we, from a privileged vantage, call regularization. But regularity is not the default state of a language. A rule is the tombstone of a thousand exceptions.

\section{Methods Summary}

We searched 11 reference works on Old and Middle English, compiling a list of every irregular verb which we found. We determined whether each verb was still present in Modern English. For all those Old English verbs whose descendants remained in the English language, we checked whether they were still irregular using a complete listing of the Modern irregular verbs. If they had regularized, we determined when regularization had occurred based on the last time period in which we found a positive annotation listing the verb as irregular. A list of sources used, and the entire resulting annotation, are provided in the Supplementary Information.

We determined usage frequencies for all the verbs using the CELEX database. We then binned the Old English irregular verbs using a standard logarithmic binning algorithm in Python. We used the resulting binning to determine regularization rates for verbs of differing frequencies. Regularization rates (Figure 1b) for each bin were computed directly. The fits to exponential decay (Figure 2) and to the solution of the Irregular equation (Figure 3, see Supplementary Information) were produced using the method of least squares. The Python source code for producing the figures and the table is available at http://www.languagedata.org.

\section{Supplementary Material}

Refer to Web version on PubMed Central for supplementary material.

\section{Acknowledgements}

The Program for Evolutionary Dynamics is sponsored by J. Epstein. E.L. was supported by the National Defense Science and Engineering Graduate Fellowship and the National Science Foundation Graduate Fellowship. We are indebted to S. Pinker, J. Rau, D. Donoghue, and A. Presser for discussions. We thank J. Saragosti for help with visualization.

\section{References}

1. Chomsky, N. Aspects of the Theory of Syntax. Cambridge: The MIT Press; 1965.

2. Lightfoot, D. The Development of Language: Acquisition, Change and Evolution. Oxford: Blackwell; 1999.

3. Clark R, Roberts I. A computational model of language learnability and language change. Linguist. Inq 1993;24:299-345.

4. Abrams D, Strogatz S. Modelling the dynamics of language death. Nature 2003;424:900. [PubMed: 12931177] 
5. Nowak MA, Komarova NL, Niyogi P. Computational and evolutionary aspects of language. Nature 2002;417:611-617. [PubMed: 12050656]

6. Hooper, J. Current Progress in Historical Linguistics. Christie, W., editor. Amsterdam: North-Holland; 1976. p. 95-105.

7. Hauser MD, Chomsky N, Fitch WT. The faculty of language: what is it, who has it, and how did it evolve? Science 2002;298:1569-1579. [PubMed: 12446899]

8. Chomsky, N.; Lasnik, H. Syntax: An International Handbook of Contemporary Research. Jacobs, J., editor. Berlin: de Gruyte; 1993. p. 506-569.

9. Dougherty, RC. Natural Language Computing. Hillsdale: Lawrence Erlbaum; 1994.

10. Stabler EP, Keenan EL. Structural similarity within and among languages. Theor. Comput. Sci 2003;293:345-363.

11. Niyogi, P. The Computational Nature of Language Learning and Evolution. Cambridge: The MIT Press; 2006.

12. Labov W. Transmission and Diffusion. Language 2007;83:344-387.

13. Pinker, S. Words and Rules: The Ingredients of Language. New York: Basic Books; 1999.

14. Kroch A. Reflexes of grammar in patterns of language change. Lang. Variation Change 1989;1:199_ 244.

15. Kroch, A. In: Beals, K., et al., editors. Papers from the 30th Regional Meeting of the Chicago Linguistics Society: Parasession on Variation and Linguistic Theory; Chicago. CLS; 1994. p. 180-201.

16. Pinker S. The irregular verbs. Landfall. 2000 March;

17. Bybee, J. Morphology: A Study of Relation Between Meaning and Form. Amsterdam: John Benjamins; 1985.

18. Greenberg, J. Current Trends in Linguistics III. Sebeok, TA., et al., editors. The Hague: Mouton; 1966. p. 61-112.

19. Bybee J. From usage to grammar: the mind's response to repetition. Language 2006;82:711-733.

20. Corbett, G.; Hippisley, A.; Brown, D.; Marriott, P. Frequency and the Emergence of Linguistic Structure. Bybee, J.; Hopper, P., editors. Amsterdam: John Benjamins; 2001. p. 201-226.

21. Hare M, Elman J. Learning and morphological change. Cognition 1995;56:61-98. [PubMed: 7634765]

22. Marcus G, Brinkmann U, Clahsen H, Wiese R, Pinker S. German inflection: the exception that proves the rule. Cognit. Psychol 1995;29:189-256. [PubMed: 8556846]

23. Van der Wouden, T. In: Magay, T.; Zigány, J., editors. Papers from the 3rd International EURALEX Congress; Budapest. Akadémiai Kiadó; 1988. p. 363-373.

24. Zipf, GK. Human Behavior and the Principle of Least Effort. Cambridge: Addison-Wesley; 1949.

25. Miller GA. Some effects of intermittent silence. Am. J. Psychol 1957;70:311-314. [PubMed: 13424784]

26. Yang, C. Knowledge and Learning in Natural Language. New York: Oxford University Press; 2002.

27. Glushko, M. Towards the quantitative approach to studying evolution of English verb paradigm; Proceedings of the 19th Scandinavian Conference of Linguistics; 2003. p. 30-45.

28. Kroch, A.; Taylor, A. Penn-Helsinki Parsed Corpus of Middle English. second edition. 2000. 

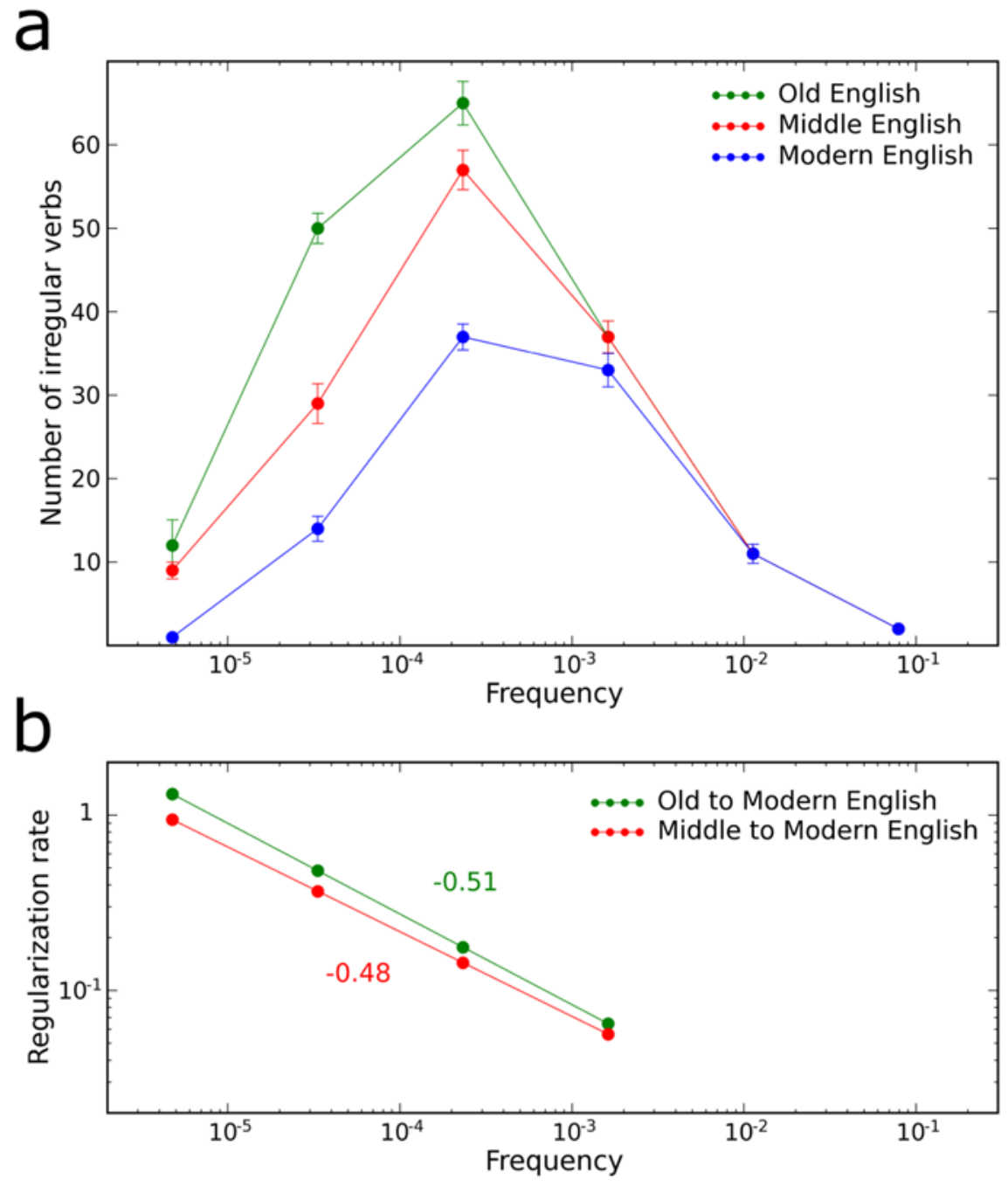

Figure 1.

Irregular verbs regularize at a rate that is inversely proportional to the square root of their usage frequency. a, The evolution of 177 verbs from Old English (green) over time, through Middle (red) and Modern English (blue). The fraction remaining irregular in each bin decreases as the frequency decreases. Frequency shown is that of the modern descendant, and was computed using the CELEX corpus. Error bars indicate standard deviation and were calculated using the bootstrap method. $\mathbf{b}$, The regularization rate of irregular verbs as a function of frequency. The relative regularization rates obtained by comparing Old vs. Modern English (green) and Middle vs. Modern English (red) scale linearly on a log-log plot with a downward slope of nearly onehalf. The regularization rate, and the half-life, scale with the square root of the frequency. 

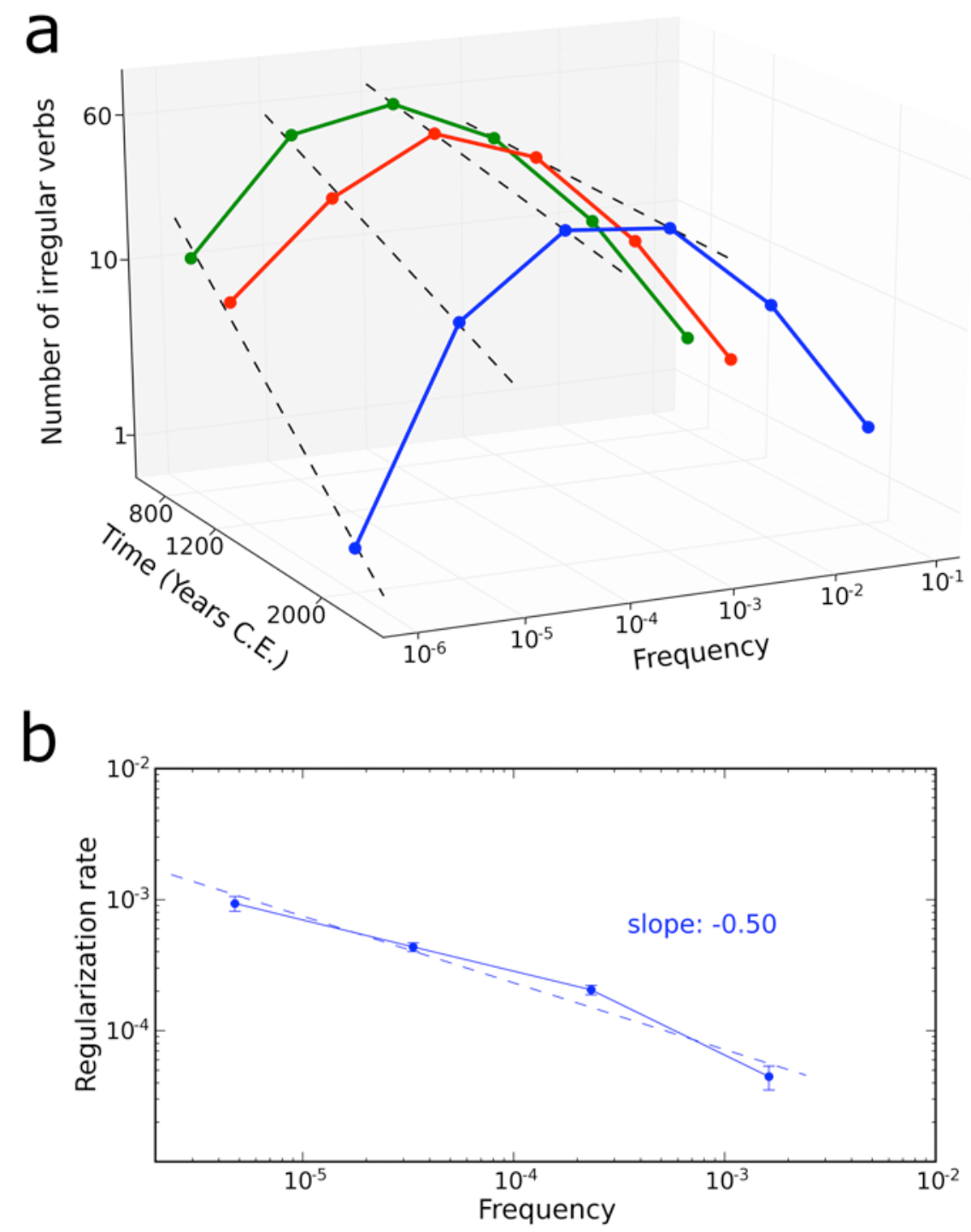

Figure 2.

Irregular verbs decay exponentially over time. a, Specifying approximate dates of Old and Middle English allows computation of absolute regularization rates. Regularization rates increase as frequencies decrease, but are otherwise constant over time. b, Absolute rates of regularization are shown as a function of frequency. Error bars indicate standard deviation and were calculated using the bootstrap method. The square-root scaling is obtained again. 


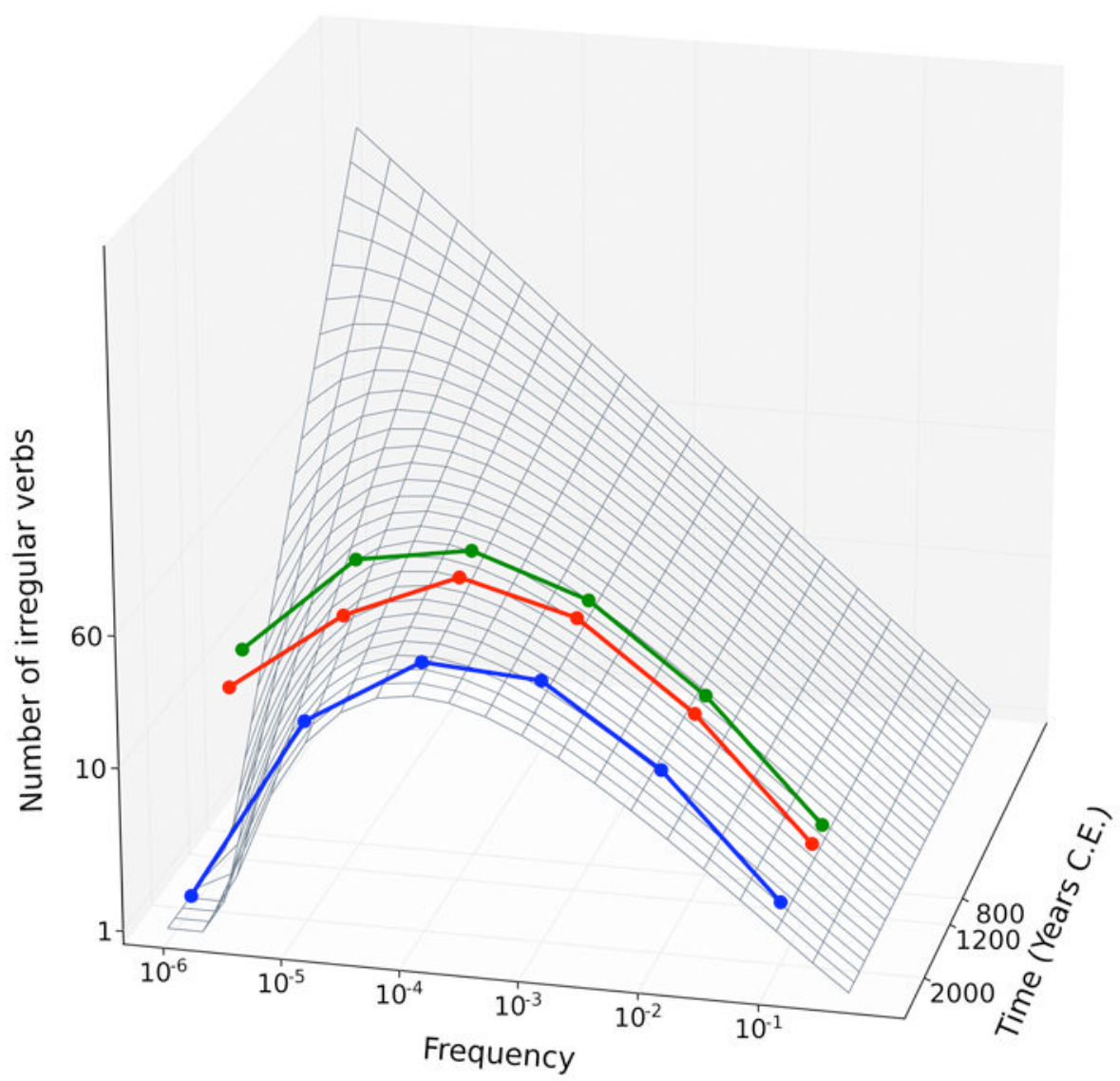

Figure 3.

Extrapolating forward and backward in time using the observation that regularization rate scales as the square root of frequency. The differential system is exactly solvable and the solution fits all three observed distributions. As we move backward in time, the distribution of irregular verbs approaches the Zipfian distribution characteristic of random sets of words. The distribution for exceptions to the - $e d$ rule became non-random because of frequency dependent regularization due to selective pressure from the emerging rule. 
The 177 Irregular verbs studied

Table 1

177 Old English irregular verbs were compiled for this study, and are arranged according to frequency bin and in alphabetical order within each bin. Also shown is the percentage of verbs in each bin which have regularized. The halflife is shown in years. Verbs that have regularized are indicated in red. As we move down the list, an increasingly large fraction of the verbs are red; the frequency dependent regularization of irregular verbs becomes immediately apparent.

Frequency

$10^{-1}-1$

$10^{-2}-10^{-1}$

$10^{-3}-10^{-2}$

$10^{-4}-10^{-3}$

$10^{-5}-10^{-4}$

$10^{-6}-10^{-5}$
Verbs

be, have

come, do, find, get, give, go, know, say, see, take, think

begin, break, bring, buy, choose, draw, drink, drive

eat, fall, fight, forget, grow, hang, help, hold, leave, let, lie

lose, reach, rise, run, seek, set, shake, sit, sleep, speak

stand, teach, throw, understand, walk, win, work, write

arise, bake, bear, beat, bind, bite, blow, bow, burn, burst carve, chew, climb, cling, creep, dare, dig, drag, flee

float, flow, fly, fold, freeze, grind, leap, lend, lock, melt, reckon

ride, rush, shape, shine, shoot, shrink, sigh, sing, sink

slide, slip, smoke, spin, spring, starve, steal, step, stretch

strike, stroke, suck, swallow, swear, sweep, swim, swing

tear, wake, wash, weave, weep, weigh, wind, yell, yield

bark, bellow, bid, blend, braid, brew, cleave, cringe crow, dive, drip, fare, fret, glide, gnaw, grip, heave

knead, low, milk, mourn, mow, prescribe, redden, reek, row

scrape, seethe, shear, shed, shove, slay, slit, smite

sow, span, spurn, sting, stink, strew, stride, swell

tread, uproot, wade, warp, wax, wield, wring, writhe

bide, chide, delve, flay, hew, rue, shrive, slink, snip spew, sup, wreak
$\%$ Reg

Half Life 